\title{
Management of Carpal Tunnel Syndrome - Surgical Vs Medical?
}

\author{
Md. Ruhul Kuddus ${ }^{1}$, Md. Omar Faruk², Samiul Alam ${ }^{3}$, K.M Atiqul Islam ${ }^{4}$, S. Alam ${ }^{5}$, Debnath H ${ }^{6}$
}

Conflict of interest: None

Funding Agency: was not funded by any institute or any group.

Contribution of Authors: None

Copyright: @2020bang.BJNS published by BSNS. This article is published under the creative commons CC-BY-NC license. This license permits use distribution (https://creativecommons. orgf/licences/by-nc/4-0/)reproduction in any medium, provided the original work is properly cited and is not used for commercial purposes.

Received: 19.11 .19

Accepted: 23.02 .20

\begin{abstract}
:
Background: Carpal Tunnel Syndrome (CTS) is the most common form of entrapment neuropathy. Both the Medical and surgical treatments are popular in the management of CTS. The effectiveness of the surgical treatment of carpal tunnel syndrome (CTS) is well known on short term. Surgical approach has proved to be more efficient relative to the conservative methods of steroid injections and splinting. On the other hand, many studies have demonstrated both advantages and adverse effects of the surgical methods. However, limited data is available about long-term outcome after carpal tunnel release (CTR). So debate is still persists regarding Conservative vs. Surgical approach to treatment of CTS.
\end{abstract}

Methods: A retrospective analysis of 15 consecutive cases performed during 1.5 year was conducted. 8 patients were treated surgically with transpalmar approach. 7 patient were treated conservatively. The criteria for treatment efficacy were improvements in symptoms, such as pain, paresthesia and recurrences after surgery.

Results: Female were predominant $80 \%$ than male 20\%. Right hand was more frequently affected $80 \%$ than left $20 \%$. most paitents were diabetic except 2 . outcome in the surgical group was excellent. Patient of non-surgical group was not satisfied as surgical group.

Conclusions: CTR is a robust treatment for CTS and its effect persists after a period of years. CTR is the choice of treatment in case of moderate to severe form of CTS. Long term follow up and inclusion of more cases is needed for a definite conclusion.

Keywords: Carpal tunnel release; Carpal tunnel syndrome; transpalmar, outcome. Bang. J Neurosurgery 2020; 10(1): 75-81

\section{Introduction:}

Carpal tunnel syndrome (CTS) is the most common entrapment neuropathy in the upper extremity $1,2,3$. The median nerve is compressed within its course through the carpal tunnel just distal to the wrist crease. Usually it occurs in middle-aged patients. Ratio of female: male $=4: 1$. It is bilateral in over $50 \%$ of cases, but is usually worse in the dominant hand and diabetics. Common features of CTS are dysesthesia, characteristically patients are awakened at night by a painful numbness in the hand. Distributions of the symptoms are on palmar side in radial 3.5 fingers.
Hypesthesia in median nerve sensory distribution, 2point discrimination may be more sensitive test ${ }^{4}$. Tinel's sign at the wrist is positive in $60 \%$ cases. Phalen's test is positive $80 \%$ cases ${ }^{5}$. Common associations of CTS are Job related trauma (repeated movement of hand e.g. carpenter, type writer) Systemic condition - DM, RA, pregnancy, obesity, hypothyroidism and local trauma ${ }^{6}$. Surgical approach has proved to be more efficient relative to the conservative methods of steroid injections and splinting. Carpal tunnel release (CTR) is one of the most frequently performed hand procedures ${ }^{7,8}$. Open

1. Dr. Md. Ruhul Kuddus, Medical Officer, Emergency Dept. of Neurosurgery, Bangabandhu Sheikh Mujib Medical University, Dhaka, Bangladesh.

2. Dr. Md. Omar Faruk, Medical Officer, Dept. of Neurosurgery, Dhaka Medical College \& Hospital, Dhaka, Bangladesh

3. Dr. Samiul Alam, Assistant Professor, Dept. of Neurosurgery, Mymensingh Medical College \& Hospital, Mymensingh, Bangladesh

4. Dr. K.M Atiqul Islam, Medical Officer, Dept. of Neurosurgery, National Institute of Neurosciences \& Hospital, Dhaka, Bangladesh.

5. Dr. Shamsul Alam, Assistant Professor, Dept. of Neurosurgery, Bangabandhu Sheikh Mujib Medical University, Dhaka, Bangladesh.

6. Prof. Hadadhan Debnath, Professor, Dept. of Neurosurgery, Bangabandhu Sheikh Mujib Medical University, Dhaka, Bangladesh. Address of Correspondence: Dr. Md. Ruhul Kuddus, Medical Officer, Emergency Dept. of Neurosurgery, Bangabandhu Sheikh Mujib Medical University, Dhaka, Bangladesh. Mobile: 01914331838, E-mail: dr.mrksikder@gmail.com 
carpal tunnel release is a common surgical treatment for carpal tunnel syndrome ${ }^{9}$. Endoscopic CTR is another popular option of the treatment of severe form of CTS. Some author showed that Endoscopic carpal tunnel release provides the similar effecacy ${ }^{10}$. Sometimes we the physician advocate splinting for the treatment of mild to moderate form of CTS. There is limited evidence that splint worn at night is more effective than no treatment in the short term, but there is insufficient evidence regarding the effectiveness and safety of splinting over non-surgical intervention for CTS ${ }^{11}$.

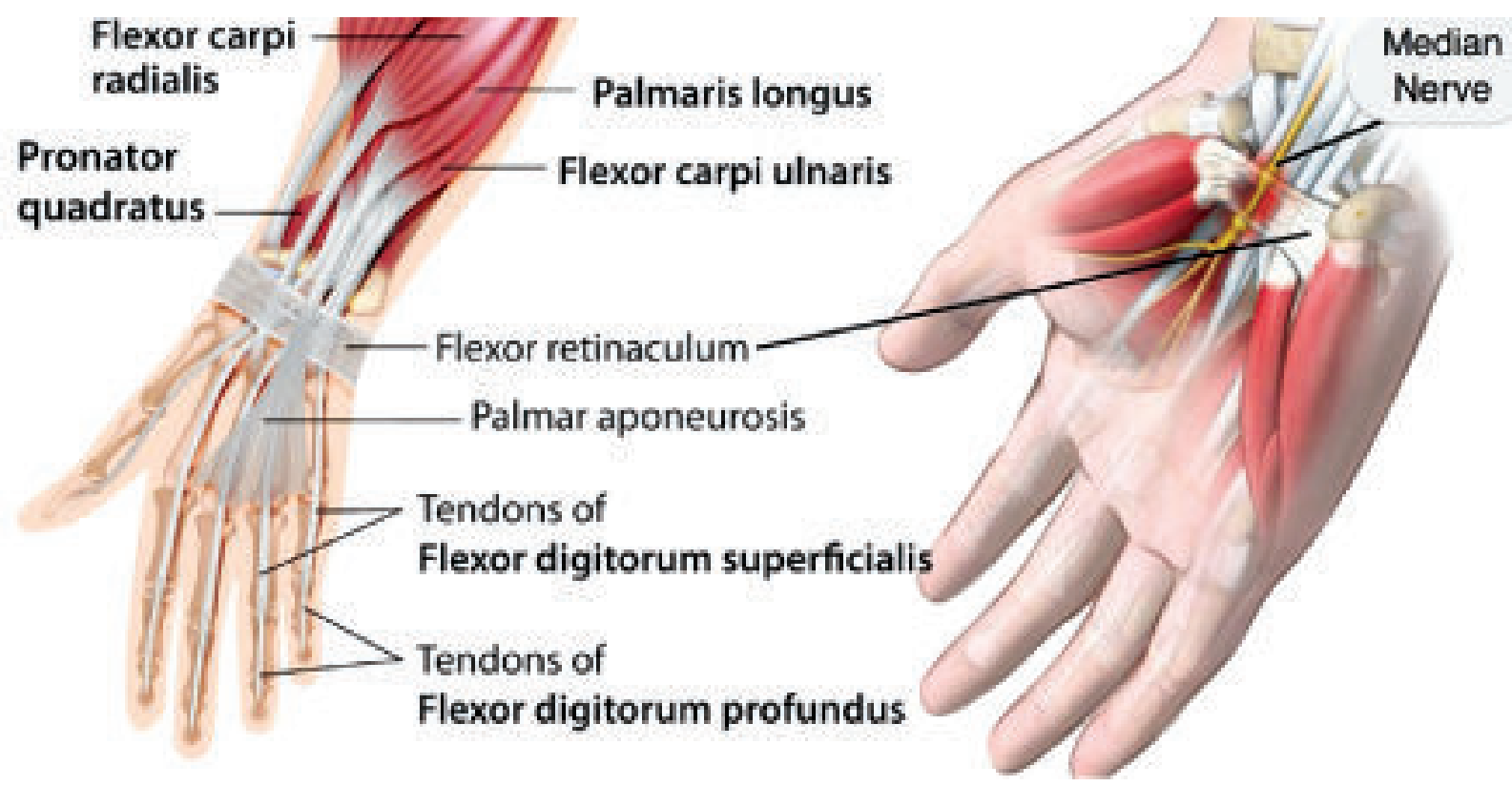

Fig.-1: Anatomy of carpal tunnel ${ }^{19}$

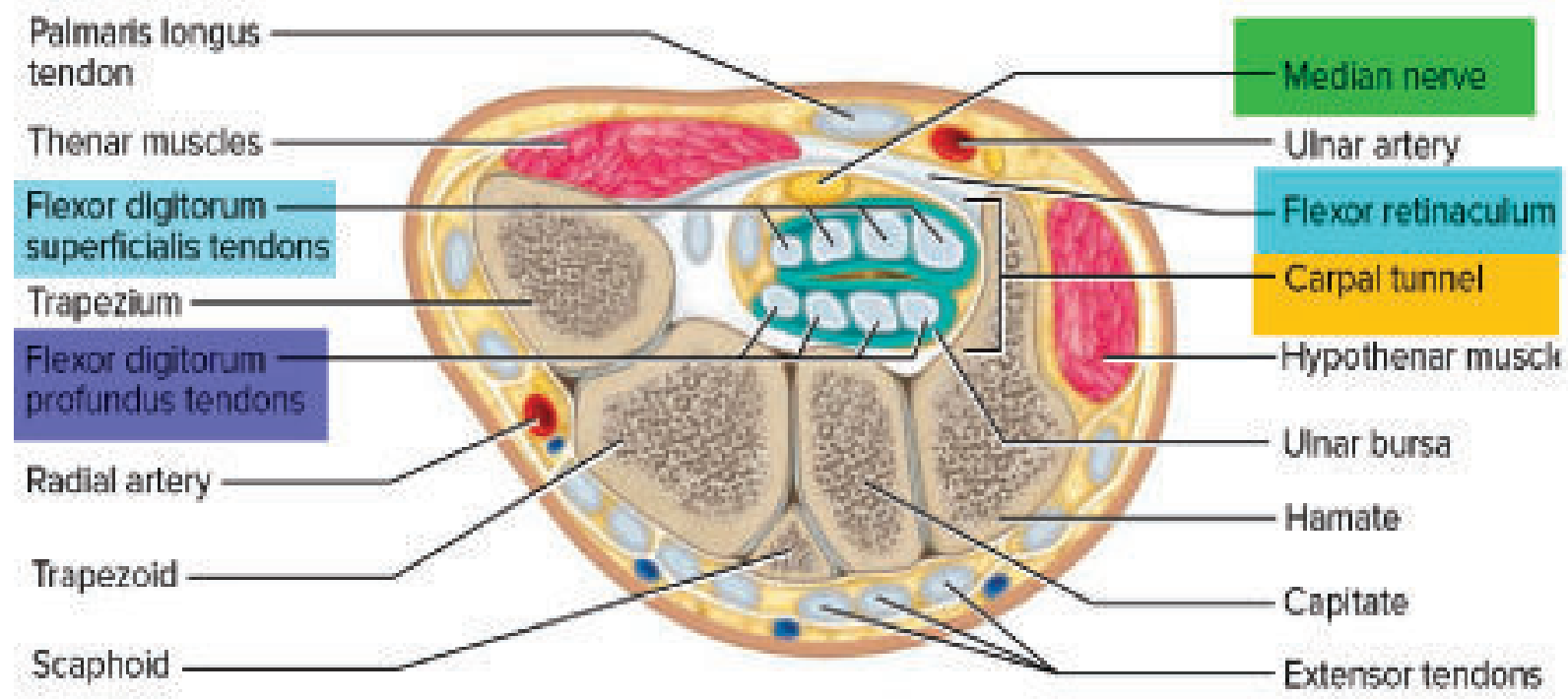

(b) Cross section

Fig.-2: Cross section anatomy of carpal tunnel ${ }^{19}$. 

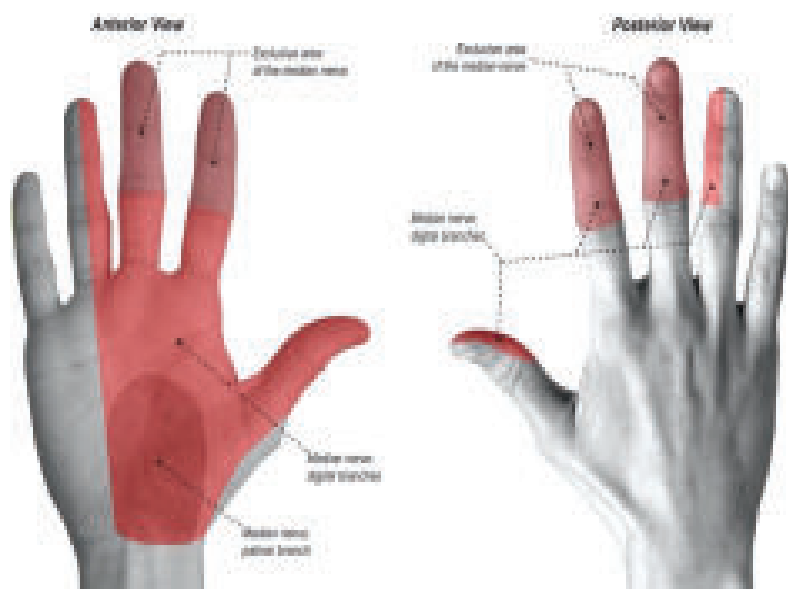

Fig.-3: Sensory distribution of median nerve ${ }^{19}$.

Tinel's sign: Light percussion (taping) over the irritated median nerve at the flexor retinaculum elicits a tingling sensation ("pins and needles") in the distribution of the nerve.

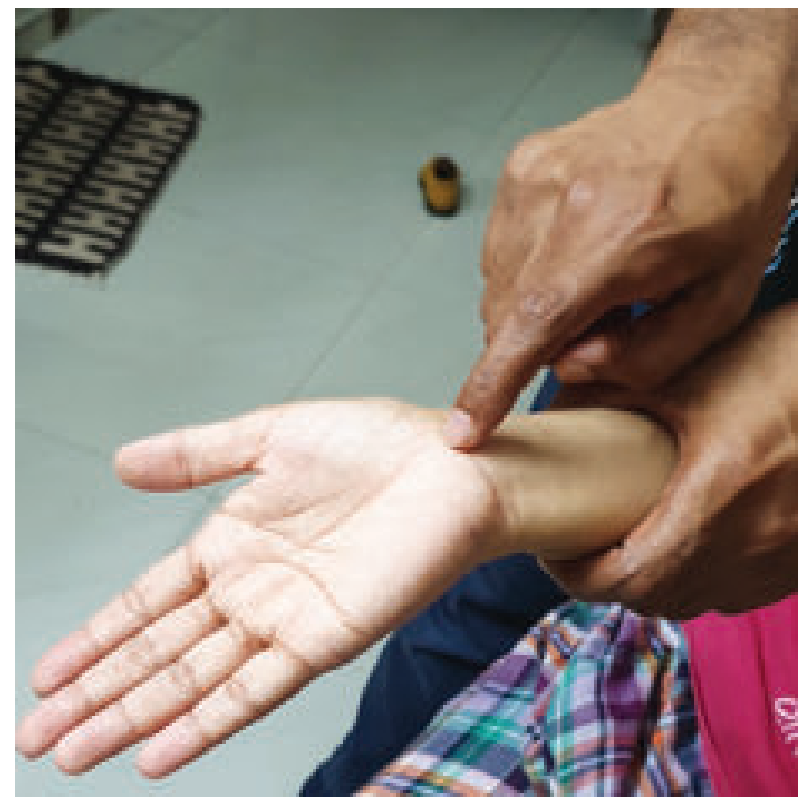

Photo was taken with kind permission of the patient

Fig.-4: Tine's sign

\section{Methods:}

This is a retrospective analytical study. The study population was recruited from two private hospitals. Total 15 cases were primarily enrolled in this study that was managed during the last $1.5 \mathrm{yrs} .7$ patients were managed medically \& 8 patients were managed surgically. Medical management includes - NSAIDs, Splinting, but I have not given steroid injection. Before

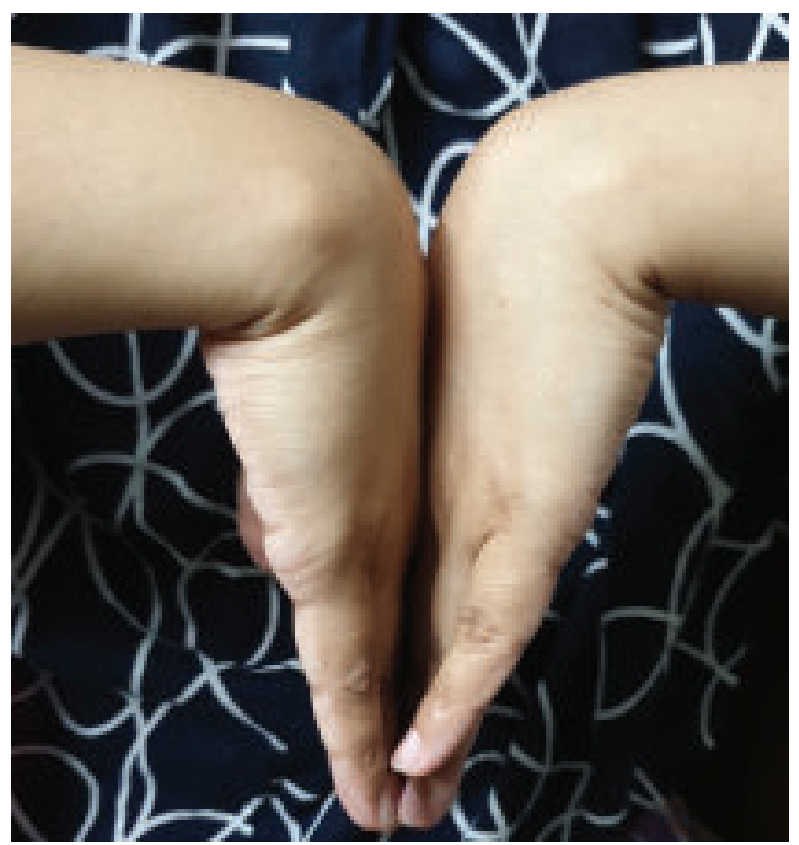

Fig.-5: Phalen's menuever: Maintained flexion of the wrist at a $90^{\circ}$ angle for 30-60 seconds reproduces CTS symptoms of tingling of pain.

going for surgery following investigations were routinely done.

Diagnostic tests:

- No investigation is conclusive, diagnosis is clinical.

- $\mathrm{CBC}$

- CRP

- Glucose

- TSH

- NCV - it helps to take decision for surgery.

- ECG

Surgical management: Open CTR was done through transpalmar approach. Mini incision surgery with plain Local anesthetic agents was used. All surgery was done as an out patient basis. I used baby needle for the introduction of LA agents. Incision was made with Number 15 blade. The wound was closed with 3-0 cutting prolene in a single layer. This is a very limited study with short duration. I follow up the patient for last 1.5 years and I assessed post-operative patient's compliance and satisfaction. Clinical examination was done post-operatively to assess the improvement. 

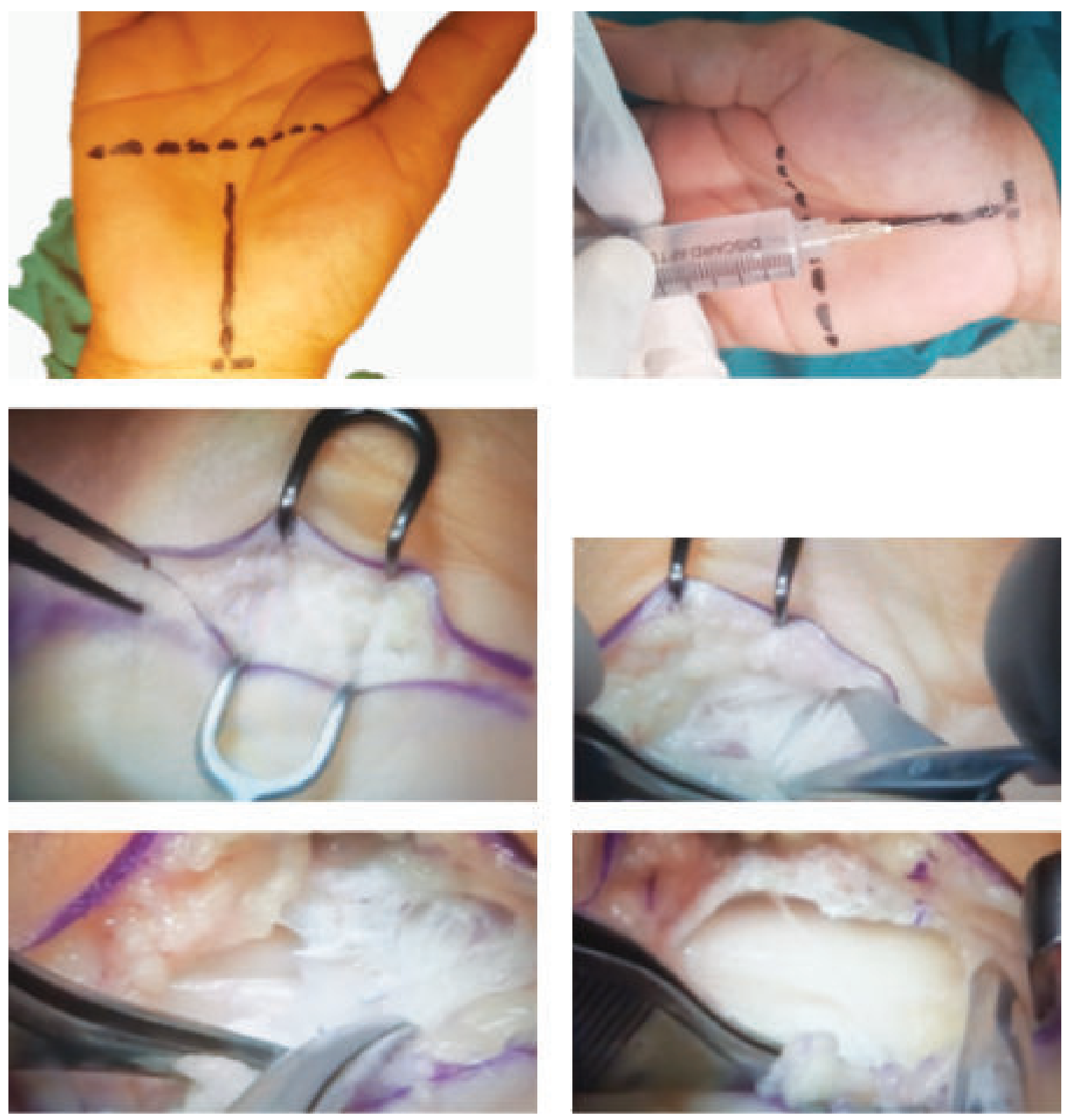

Fig.-6: Steps of surgery

\section{Results:}

Table-I

Distribution of the patient according to the age

\begin{tabular}{lc}
\hline Age range $(Y)$ & Number of the patient \\
\hline $30-40$ & $2(13 \%)$ \\
$41-50$ & $3(20 \%)$ \\
$51-60$ & $8(53 \%)$ \\
$61-70$ & $2(13 \%)$ \\
\hline Total & $15(100 \%)$ \\
\hline
\end{tabular}

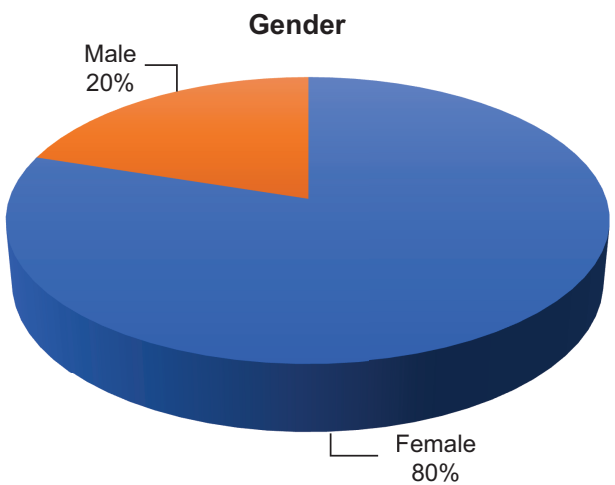

Fig.-7: Diagram shows Male: Female $=4: 1$ 
Table-III

Distribution of the patient according to the presenting complaints

\begin{tabular}{lc}
\hline Clinical features & Number of the patients \\
\hline Night pain & $15(100 \%)$ \\
Tingling and numbness & $15(100 \%)$ \\
Weakness of hand grip & $8(53 \%)$ \\
Thenar atrophy & $8(53 \%)$ \\
Clumsiness & $12(80 \%)$ \\
Hypesthesia (loss of 2 point discrimination and poor pin prick sensation & $12(80 \%)$ \\
in radial 3.5 fingers) & $13(86 \%)$ \\
Phalen's maneuver & $10(66 \%)$ \\
Tinel's test & \\
\hline
\end{tabular}

Table-IV

Outcome of the patients according to treatment modality.

\begin{tabular}{lcll}
\hline Rx modality & Number of patients & Level of satisfaction & Follow up \\
\hline Surgical & 8 & $\begin{array}{l}7 \text { patients were } \\
\text { highly satisfied }\end{array}$ & $\begin{array}{l}\text { On short-term follow up only 1 patient had } \\
\text { the complain of some degree of weakness }\end{array}$ \\
Medical & 7 & $\begin{array}{l}\text { No patients were } \\
\text { satisfied even after } \\
\text { using splint }\end{array}$ & $\begin{array}{l}\text { After stop medication and splint, } \\
\text { symptoms recurred }\end{array}$ \\
\hline Total & 15 & & \\
\hline
\end{tabular}

Result and observation: Total 15 patients were enrolled in this study. Female: Male $=4: 1$. Common presenting complaints were pain, especially at night and tingling and numbness in the median nerve distribution. Phalen's maneuver is a specific and sensitive test for severe form of CTS. Regarding investigation NCV is very much helpful to take decision

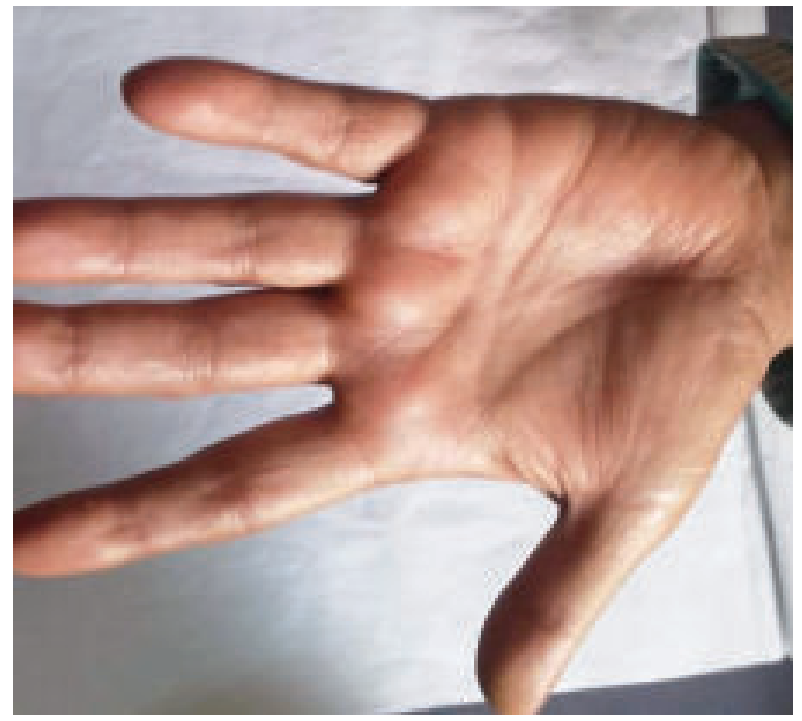

Fig.-7 for surgery. Patients of surgical group were highly satisfied where the patients treated with medical management and splinting were not satisfied, although they have transient improvement.

Follow up: On follow-up after $1.5 \mathrm{yr}$, patient has no scar mark. One patient has partially improved her thenar atophy (fig-7).

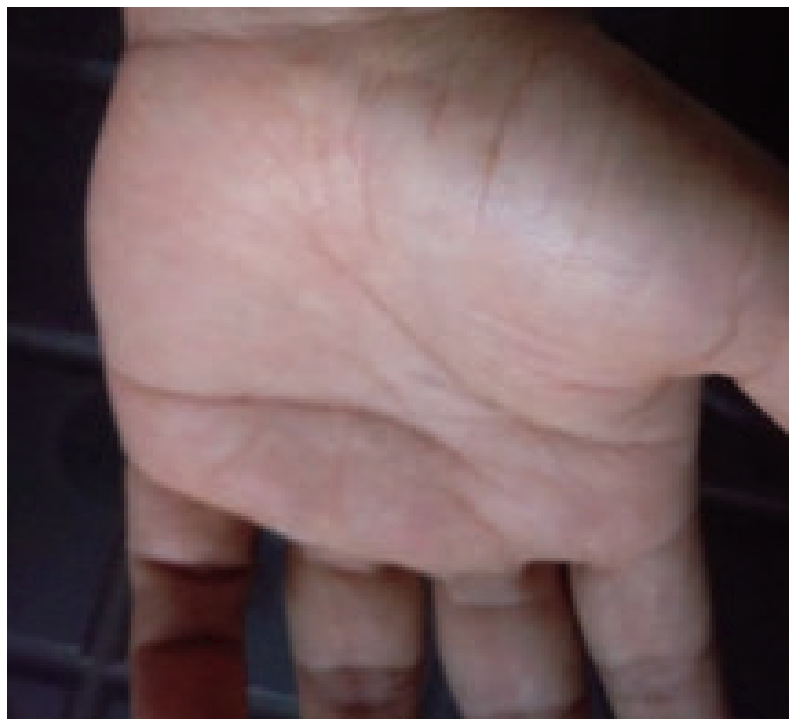

Fig.-8 


\section{Discussion:}

In our study, female were significantly dominant than male. Diabetes was the common association with CTS. Common presenting symptoms were pain, tingling, numbness, and decreased sensation in the median nerve distribution. Phalen's and tinel's test are helpful for

diagnosis. NCV is the only investigation that is helpful to distinguish the disease severity and to take decision for surgery. Important finding of this study is the outcome of conservative treatment and surgical treatment. On follow-up the outcome of surgical treatment (open CTR) was encouraging. On the other hand, splinting and NSAIDS has transient benefits and relief from pain.

The results of the present study show that long-term results of open carpal tunnel release are favorable. Eighty- seven percent of patients reported good symptom scores ( $<2$ points) and $74 \%$ reported good function scores ( $<2$ points). Eighty-eight percent of the patients were completely or very satisfied. We hypothesized that nocturnal pain, which is characteristic of nerve irritation due to carpal tunnel syndrome, will be present in a small minority of patients. The problems reported more frequently, such as daytime pain, weakness, and trouble opening jars, are less specific to carpal tunnel syndrome and may be attributable to other comorbidities such as osteoarthritis or rheumatoid arthritis. Our finding that carpal tunnel syndrome confounding comorbidities, such as rheumatoid arthritis, diabetes mellitus, polyneuropathy, and osteoarthritis, are associated with pain and function scores supports this hypothesis ${ }^{12}$.

While numerous studies have noted the excellent early ${ }^{13,14}$ results of open carpal tunnel release, the durability of clinical results has remained uncertain. A recent study 15 has claimed that surgical outcomes after five years were only marginally better than nonsurgical outcomes. Other studies have described noticeable returns of at least some preoperative symptoms, on the order of $57 \% 16$ and $25 \% 17$.

Another study suggests that the long-term results of open carpal tunnel release are excellent, with patients experiencing consistent pain relief over ten to fifteen years. The rate of re- operation was very low, at $1.8 \%$. A high percentage of patients reported excellent results, high levels of satisfaction, and improvements in their quality of life ${ }^{12}$.
CTR has a favorable outcome and good rates of satisfaction, even in patients with bilateral severe CTS at a mean of nine years after surgery. Endoscopic CTR has a higher rate of numbness resolution than open surgery. There were no significant differences in outcome between the dominant and non-dominant hand ${ }^{18}$.

\section{Limitations}

- Very limited number of patients

- Short term follow-up

Take home message

- Surgical results of peripheral nerve disorders are very encouraging \& rewarding.

- So every neurosurgeon can entertain all kinds of peripheral nerve surgery.

\section{Conclusion:}

CTR is the choice of treatment in case of moderate to severe form of CTS. Long-term follow up and inclusion of more cases is needed for a definite conclusion.

\section{Reference:}

1. Stewart JD. In: Median Nerve. Focal Peripheral Neuropathies. 4th ed. West Vancouver, Canada: JBJ Publishing; 2010:214-239

2. Yasargil MG, Antic J, Laciga R, et al. Microsurgical Pterional Approach to Aneurysms of the Basilar Bifurcation. Surg Neurol. 1976; 6

3. Atroshi I, Gummesson C, Johnsson R, Ornstein E, Ranstam $\mathrm{J}$, Rosen I. Prevalence of carpal tunnel syndrome in a general population. JAMA. 1999; 282:153-158

4. GREENBERG, M., MARK S. (ed.) 2016. Handbook of Neruosurgery, New York: Thieme, 519-526.

5. Phalen GS. The Carpal Tunnel Syndrome. Clinical Evaluation of 598 Hands. Clin Ortho Rel Res. 1972; 83

6. Feldman RG, Goldman R, Keyserling WM. Classical Syndromes in Occupational Medicine: Peripheral Nerve Entrapment Syndromes and Ergonomic Factors.AmJIndMed.1983;4:661-681

7. Mosier BA, Hughes TB. Recurrent carpal tunnel syndrome. Hand Clin. 2013; 29:427-434

8. Jain NB, Higgins LD, Losina E, Collins J, Blazar PE, Katz JN. Epidemiology of musculoskeletal upper extremity ambulatory surgery in the United States. BMC Musculoskelet Disord. 2014; 15. DOI: 10.1186/ 1471-2474$15-4$

9. Hankins CL, Brown MG, Lopez RA, Lee AK, Dang J, Harper RD. A 12-year experience using the Brown two-portal endoscopic procedure of transverse carpal ligament release in 14,722 patients: defining a new paradigm in the treatment of carpal tunnel syndrome. Plast Reconstr Surg. 2007 Dec; 120(7): 1911-21. 
10. Vasiliadis HS, Xenakis TA, Mitsionis G, Paschos N, Georgoulis A. Endoscopic versus open carpal tunnel release. Arthroscopy. 2010;26(1):26-33.

11. Page MJ, Massy-westropp N, O'Connor D, Pitt V; Splinting for carpal tunnel syndrome; Cochrane Database Syst Rev, CD010003.

12. Louie DL, Earp BE, Collins JE, Losina E, Katz JN, Black EM, et al. Outcomes of open carpal tunnel release at a minimum of ten years. J Bone Joint Surg Am. 2013;95 (12):106773.

13. Atroshi I, Hofer M, Larsson GU, Ornstein E, Johnsson R, Ranstam J. Open compared with 2-portal endoscopic carpal tunnel release: a 5-year follow-up of a randomized controlled trial. J Hand Surg Am. 2009;34(2):266-72.

14. Jacobsen MB, Rahme H. A prospective, randomized study with an independent observer comparing open carpal tunnel release with endoscopic carpal tunnel release. J Hand Surg Br. 1996;21(2):202-4.

15. Pensy RA, Burke FD, Bradley MJ, Dubin NH, Wilgis EF; A6year outcome of patient who cancelled carpal tunnel surgery, J Hand Surg Eur Vol.2011 Oct; 36(8): 642-

16. Semple JC, Cargil AO. Carpal tunnel syndrome. Result of surgical decompression. Lancet. 1969 May 3;1 (7601): 918-9.

17. Nancollas MP, Peimer CA, Wheeler DR, Sherwin FS. Longterm results of carpal tunnel release. J Hand Surg $\mathrm{Br}$. 1995 Aug: 20(4); 470-4.

18. Tang CQY, Lai SWH, Tay SC; Long-term outcome of carpal tunnel release surgery in patient with severer carpal tunnel syndrome. Bone Joint J 2017; 99-B:1348-53.

19. https://www.healthproductsforyou.com/ prodimages/ Optimize CommonImage/ 31520182218 carpal_tunnel_1gen.png 